\title{
Burge on Perception and the Disjunction Problem*
}

\author{
Jon Altschul
}

Received: 24/02/2014

Final Version: 22/12/2014

BIBLID 0495-4548(2015)30:2p.251-269

DOI: $10.1387 /$ theoria. 11008

ABSTRACT: According to the Disjunction Problem, teleological theories of perceptual content are unable to explain why it is that a subject represents an $F$ when an $F$ causes the perception and not the disjunction $F v G$, given that the subject has mistaken G's for F's in the past. Without an adequate explanation these theories are stuck without an account of how non-veridical representation is possible, which would be an unsettling result. In this paper I defend Burge's teleological theory of perception against the Disjunction Problem, arguing that a perceptual state's representing what I call an error-prohibiting disjunctive property is incompatible with the truth of perceptual anti-individualism. And because perceptual anti-individualism is at the heart of Burge's theory, I conclude that Burgeans need not be concerned with the Disjunction Problem.

Keywords: Perception, Representation, Disjunction Problem, Tyler Burge, Anti-individualism.

RESUMEN: Según el Problema de la Disyunción, las teorías teleológicas del contenido perceptual son incapaces de explicar por qué un sujeto se representa un $\mathrm{F}$ cuando es un $\mathrm{F}$ el que causa la percepción y no la disyunción $\mathrm{F}$ v G, dado que en el pasado el sujeto ha confundido G con F. Sin una explicación adecuada, estas teorías se quedan estancadas sin dar cuenta de cómo es posible la representación no verídica, lo que sería un resultado inquietante. En este artículo defiendo la teoría teleológica de la percepción de Burge frente al Problema de la Disyunción. Argumento que un estado perceptual que represente lo que llamo una propiedad disyuntiva que prohíbe el error es incompatible con la verdad del anti-individualismo perceptivo. Y, puesto que el anti-individualismo perceptivo es central en la teoría de Burge, concluyo que los burgeanos no tienen por qué preocuparse del Problema de la Disyunción.

Palabras clave: Percepción, Representación, Problema de la Disyunción, Tyler Burge, Anti-Individualismo.

\section{Introduction}

Tyler Burge's theory of perception, for which he has argued for several decades and which culminates in his recent book (2010), holds that the perceptual system is a representational system whose function is to produce veridical representations in the subject's home environment. Accordingly, as I will explain, Burge is committed to the following principle:

(VER) Each perceptual state is associated with a veridicality condition; an instance of a perceptual state type may be veridical, while a different instance of that same type, in a different context, may be non-veridical.

* I would like to thank the following for their valuable comments on earlier versions of this paper: Joe Berendzen, Ben Bayer, Leonard Kahn, Luke Manning, Kevin Morris, the participants at the second annual Southern Epistemology Conference, and the two anonymous reviewers at this journal. 
The Disjunction Problem, introduced by Fodor (1984) in its modern guise, exposes a serious shortcoming both for causal and for teleological theories of perceptual content. ${ }^{1}$ Specifically, if one attempts to ground one's theory of content in reliable causal interactions with the environment, ${ }^{2}$ or in the normal functioning of the system that produces the token, ${ }^{3}$ then it is not at all obvious how one's theory can conform to VER. For however one's theory fleshes out one's "reliable cause" condition or one's "normal functioning" condition, the Disjunction Problem reveals that for any description D of a perceptual state, such that the theory takes $\mathrm{D}$ to be non-veridical, there will always be some description $\mathrm{D}^{*}$ of the content of one's mental token that seems to satisfy the relevant condition just as well as D but that also comes out veridical upon analysis. Answering the problem demands that one give a suitable explanation as to why $\mathrm{D}$, a fallible description of the perceptual content, is a preferable description to $\mathrm{D}^{*}$, an infallible description. Without it, VER must be forfeited, which would be an embarrassing result for people like Burge.

This brings us to the primary question of this paper: Does Burge have a suitable answer to the Disjunction Problem? The problem is addressed head-on in his recent book (2010, pp. 319-326), but his discussion is rather brief and some have questioned the extent to which his answer really is satisfying. ${ }^{4}$ My aim is to defend Burge's theory of perception against the Disjunction Problem. Specifically, I will argue that on the Burgean view, D*type descriptions cannot be correct descriptions of perceptual contents, for the reason that $D^{*}$-type descriptions are incompatible with Burgean perceptual anti-individualism. Anti-individualism is at the heart of Burge's rich and complex theory of perception. So if this incompatibility claim can be defended, which I intend to do, Burgeans will have good reason not to take the Disjunction Problem too seriously. Section 2 provides an overview of Burge's theory and explains how perceptual anti-individualism is supposed to contribute to the individuation of perceptual states. In Section 3 I show that Burge's commitment to VER is presupposed in the very conditions for objective representation, the most frequently discussed by Burge being our abilities to perceive constancies. Section 4 returns to the Disjunction Problem where I argue that Burge has grounds for dismissing it. Lastly in Section 5 I respond to several objections.

\section{Burge on Perception}

Let us begin by highlighting those features of Burge's theory that will be most useful for our purpose of answering the Disjunction Problem later on. To say that the perceptual system is a representational system implies that perceptual states are representational states and, as such, each state type is to be distinguished by its representational content. In accordance with VER, each perceptual representational state is associated with a veridicality condition, a condition under which that state is veridical. Let us say that $S$ 's perceptual representation

1 The Disjunction Problem is not just a problem for theories of perceptual content in particular, but for those concerning mental representational content in general. For our purposes, however, we will confine our discussion to the way in which the problem applies specifically to perceptual contents.

2 See for example Stampe (1977) and Dretske (1981).

3 See for example Millikan (1984 \& 1989) and Neander (1995).

${ }^{4}$ See for example Gauker (2012). 
of object $\mathrm{O}$ as being $\mathrm{F}$ is veridical just in case $\mathrm{O}$ is the cause of $\mathrm{S}$ 's representation, and $\mathrm{O}$ indeed has the properties that $S$ attributes to $\mathrm{O}$ in experience. What, then, are the conditions under which the perceptual system is capable of producing a representation with a given content (e.g. representing $\mathrm{O}$ as red or as moving downward or as food)? According to Burge which types of representational states a perceptual system is capable of exemplifying partially depends on the history of that system. As he has been defending throughout his career (1982, 1986a, 1986b, 2003a, 2005, 2007, 2010), states with representational contents are necessarily anti-individualistically individuated. According to Burge, perceptual anti-individualism

...is the view that the individuation and nature of perceptual states and beliefs are necessarily associated with relations between the perceiver and aspects of the environment. The nature of a perceptual state, as marked by its representational content, is partly determined by relations between the perceptual system, perhaps in its evolutionary history, and features of the environment that cause instances of its states and that states of the system represent. (2003a: 511)

Through its evolutionary development the perceptual system comes into causal contact with items in the environment; the history of causal interactions in the development of a representational capacity help determine that which exercises of the capacity function to represent. Individual representational abilities require not only a background of causal interactions with features of the environment. At least some of these interactions need to be successful, such that the item with which the subject interacts corresponds to the representational content of the state that that item causes.

Perceptual anti-individualism on the Burgean view falls under the heading of content externalism, which holds that a perceptual state type is the kind of state that it is in virtue of past subject-environmental interactions, but also that "[p]erceptual-state kinds are typeidentified in terms of their representational content." (2005: 19) Of course, not all forms of anti-individualism endorse content externalism. A disjunctivist or a naïve realist about perception could deny that perceptual states have any representational contents at all yet maintain that such states are individuated, in part, by subject-environmental causal interactions. 5 So it is crucial for us to understand that on the Burgean view the history of causal interactions help to establish the content of that type of perceptual state, that is, the nature of that state.

Perceptual states are constrained not by just any environment in which the subject happens to reside. The relevant environment, on the Burgean view, is the home environment, the "environment that determines the natures of representational kinds in the perceptual system.” (2005: 4) Thus, the home environment might be where the subject lives at the present time, but it need not be. It could be where the subject's phylogenetic ancestors lived, and the interactions between her ancestors and items in their environment are what explain the subject's present representational capacities. Indeed, the relevant content-individuating interactions may have been realized by ancestors that did not even have perceptual systems at all. (Burge 2010: 321)

Successful interactions, as a minimal requirement on content individuation, are indispensable to the perceptual system because they help to establish conditions for veridical-

5 See Campbell (1987). 
ity, conditions for success. The perceptual system is a success-oriented system. It is in the business of getting things right. Given various distal and proximal stimulation the perceptual system will perform properly or improperly. Even when it gets things wrong, as when it fails to satisfy one of its state's veridicality conditions, this can only be explained in connection to some standard for getting things right. This is all to say that the perceptual system has a characteristic function, and it can adequately or inadequately carry out that function. The objects, properties, and relations in the environment with which the perceptual system has interacted in the past help determine what the system has the function to do.

Burge's theory also has a naturalistic flavor in that any object or property represented in perception "enters into explanation of animal agency-eating, navigating, mating, fleeing." (Burge 2003b: 297) To be a perceptual state, that state must serve some use to the subject. The relevant kinds of content-individuating interactions are therefore those that have special ties to the subject's tasks and aims relating to the environment in which the content is established; these tasks and aims are primarily biological. (Burge 2003a: 508, 2003b: 297, 2005: 5, 2010: 302 $)^{6}$ Of course, this is not to say that we can explain the good of each perceptual state solely in terms of how they help to promote a creature's biological fitness. Biological or other more basic systems make an explanatory contribution to the origin and evolution of psychological systems; they play a role in determining the nature of the psychological system's function. The perceptual system could not have the function that it has if it had not developed as providing a way of coping with its environment and fulfilling more basic goals and tasks, like finding food and avoiding predators. The presence of various biological functions is therefore a necessary causal antecedent to the development and presence of psychological systems and their characteristic functions. If the biological makeup of a creature had been different, or if the creature had been assigned a different set of biological functions, the perceptual system might not have ever evolved. But this is not to say that perceptual functions are identical to, or even reducible to, biological functions. ${ }^{7}$ The perceptual system has a representational function, and as such, it is apriori attached to the representational good: veridicality. (Burge 2003a: 508)

As we proceed let us therefore understand Burgean anti-individualism to be the view that perceptual states are individuated in terms of their representational contents, where these contents are determined, in part, by a set of subject-environmental causal interactions that occurred in the subject's home environment. The relevant, content-individuating interactions are those that played a non-accidental role in the evolution of the perceptual system and which establish the function of that perceptual state.

\section{Veridicality, Constancies, and Underdetermination}

Recall that according to VER an instance of a perceptual state type may be veridical, while a different instance of that same type, in a different context, may be non-veridical. Being

${ }^{6}$ For further discussion on the requirement that perceptual states serve some use to the animal having that state in navigating through environment, see Burge's helpless sea creature example (2003b: 298).

7 Burge's attack on what he calls Deflationary Tradition of mental representation (2010: 292-4) is further defended in Rescorla (2013). See also Schulte (2013) for a teleosemanticist's response to Burge on this score. 
able to accommodate VER is key to answering the Disjunction Problem, which I address in the next section. What are Burge's own reasons for endorsing VER? This is the question I would like to address here.

For Burge the reason why it must be that perceptual states can be either veridical or non-veridical is that a denial of this distinction directly conflicts with findings in perceptual psychology. (Burge 2005) Consider what he takes to be the "primary problem for the psychology of visual perception." (2010: 89) The problem for vision psychologists is to be able to explain how the visual system manages to convert information pertaining to a twodimensional array of proximal stimulation registered on the retina into a perceptual representation with a specific, three-dimensional objectified subject matter. To understand this problem's solution we must look first at a separate, though related, problem, which Burge labels the underdetermination problem. Vision psychologists have demonstrated that a given array of proximal stimulation within the retina is too unspecific to determine a unique distal cause, since any one proximal stimulus is compatible with a plethora of alternative distal causes. The visual system therefore faces the challenge of "figuring out" 8 what to represent, given that its retinal activation is underdetermined. How does the system overcome this problem? It solves the problem by establishing what Burge refers to as formation principles. Based on various cues that are provided by other sources of input within the brain (e.g. orientation of the head or information gathered from other sense modalities), the perceptual system relies on the formation principles to interpret the input and, moreover, represent the relevant unique and crucial feature within the environment.

That the perceptual system utilizes these principles to solve the problem of underdetermination explains how the system is able to solve the "primary problem." Overcoming this problem of underdetermination is perhaps most vividly exemplified by the phenomenon of perceptual constancies, an ability found in creatures like you and me to represent the same object or property across a range of radically different proximal stimulations. (2005: 10, 2010: 114 \& 387-388) Consider one of Burge's own examples on this score regarding lightness constancy. The perceptual system is generally very good at representing a surface in the environment as having a constant degree of achromatic lightness or color with respect to its illumination, even when certain portions of the surface are illuminated more brightly than others (as when one's reading lamp shines on an isolated portion of a white piece of paper). Perceiving uniform lightness depends on the perceptual system's capacity to compute discontinuities of lightness intensities registered by photoreceptors within the retina. These discontinuities are called luminance contours (or LC for short). The problem is that a LC in the retina may be produced by a change in materials or colors along the surface of a perceived object (called reflectance edges, or RE for short), as when a bottle of ink spills over a white page or a surface has two different shades of color; but the LC may also be produced by different amounts of light striking a single surface of the same color (called illumination edges, or IE for short), as when a shadow is cast on a portion of the page. If an IE, rather than a RE, is responsible for the LC in the retina, the perceptual system should represent

${ }^{8}$ Of course, the system does not literally figure out anything, insofar as figuring something out requires cognitive capacities like learning, inferring and deciding-three capacities that the perceptual system surely lacks. To avoid confusion, let the scare quotes around the expression here and at other places in the text be taken to mean that the expression is merely metaphorical. 
the object as having a uniform degree of lightness. To discriminate an IE from a RE, the perceptual system capitalizes on various available formation principles or heuristics. For example, fuzzy edges, as opposed to sharp edges, tend to be a sign that the luminance contour was caused by an IE rather than a RE. Or, if there is a variation of perceived depth between the two sides of the edge (due, say, to a slanted orientation of the surface), this is taken to be a sign of an IE rather than a RE. Finally, if the ratio of the change in light intensity between the two sides of the edge is greater than 10:1, the system computes this as a sign that an IE is responsible for the LC.?

Let us get back to our earlier question, which was why Burge accepts VER. The answer is rooted in the fact that proximal stimulations in the retina underdetermine a unique distal cause. With the aid of certain formation principles, the perceptual system tends to be fairly reliable at picking out the correct cause of the experience. This process, however, is not infallible. There is always the possibility of "fooling" the system into misrepresenting its scene by altering the values upon which the relevant formation principles compute, whether it is due to deliberate manipulation in a controlled setting or to some anomalous event spurring from the environment. For instance, if one casts a spotlight that produces extremely sharp edges onto a portion of the sidewalk, the principle that guides formations of perceptual states pertaining to the luminosity of the sidewalk's surface will lead the perceiver astray. (Burge 2005: 15 and 2010: 353) The luminance contour will be registered by the perceptual system as a reflectance edge, and so the system will non-veridically represent the surface as having a different set of materials or colors at the portion where the sharp spotlight shines.

As I say, barring special illusory circumstances like the sharp spotlight example above, the perceptual system is generally reliable when it operates in accordance with pertinent formation principles. What grounds the system's reliability? Crucially, the answer once again comes in the form of perceptual anti-individualism. The formation principles in accordance with which the system generates perceptual states are encoded into the system against an evolutionary background of the perceptual system, of how the system interacted with features in the home environment and developed the means by which to overcome various obstacles, such as the underdetermination of retinal stimulation. The best explanation for why the system ought to represent, say, uniform lightness on a surface when it registers a fuzzy, rather than sharp, edge on the retina is that fuzzy edges are in fact indicative of uniformities of lightness in the environment. The perceptual system picks up on this law-like regularity present in the home environment insofar as its interpretation of the proximal stimuli is in adherence to some formation principle. The antiindividualistic nature of perception therefore ensures that the kinds of entities present in the home environment help to shape the formation principles that guide the generation of perceptual states. Thus, Burgean perceptual anti-individualism is that element which provides that crucial link between natural regularities present in the subject's home environment and the formation principles that help to generate her perceptual states. (2005: $19 \& 2010: 346)$

9 See Burge (2005: 9-21, 2010: 351-354) and Palmer (2002: 122-33) for more detailed discussion of how the perceptual system acquires these cues and acts on formation principles. 


\section{Burge on the Disjunction Problem}

Having highlighted a number of the main themes of Burge's theory of perception, we turn now to the Disjunction Problem and the extent to which Burge has an answer. Why does the Disjunction Problem pose a challenge to VER? To begin, let us consider a rather crude causal account of perceptual content, according to which $\mathrm{R}$ is a representation of $\mathrm{F}$ if and only if F's are causally correlated with R's. Thus we may say, to use a frequently discussed example, that a frog's visual experience represents a fly in virtue of the fact that the distal stimulus causing this experience is a fly and that other such experiences in the past have been caused by flies as well. However, it is clear that R's are sometimes caused by G's that are non$\mathrm{F}$, as it is surely possible for the frog's fly experience to be triggered by a black pellet of dust or a tiny beebee. And in these sorts of cases, we should like to say that it has a non-veridical experience; the experience represents $\mathrm{F}$, but this representation does not correspond with any $\mathrm{F}$ in the environment and so the state's veridicality condition has not been met. The problem is that on the crude causal account, this desired outcome is out of reach. For while R may be causally correlated with F's (e.g. flies), it is evident that $\mathrm{R}$ bears an even higher correlation with the disjunction: F v G (e.g. flies-or-beebees) (hence the name "Disjunction Problem"). That being the case, our causal account is forced to admit that one's experience represents not $F$, but F v G. And if this is so, then one's experiences all turn out to be veridical, whether they are caused by an F or a $\mathrm{G}$ (or anything else for that matter). The problem is that, to borrow a term from Fodor (1984 \& 1990), there is no room for any "wild tokenings" associated with each type of perceptual state, according to which a perceptual state token is triggered by some distal stimulus that does not correspond to the state's representational content. Hence, perceptual states turn out to be infallible on this account, which entails the denial of VER.

Now in order to answer this problem, we need not hold the stronger (and likely implausible) claim that perceivers can never represent disjunctive properties. Perhaps some of our own perceptual capacities do admit of disjunctive contents; where we do not perceptually discriminate between X's and Y's, it may be that our associated type of representational ability includes picking out either X's or Y's. So the extension of this representation type is disjunctive. For our purposes, we are not interested in these sorts of disjunctive representations, which I will call benign disjunctive representations, because there are acceptable empirical reasons for why the subject represents the entire disjunction as opposed to any of its isolated disjuncts. Our interests lie instead with what I will call error-probibiting disjunctive representations (or EP disjunctive representations hereafter). An EP disjunctive representation is one in which the subject is no better or worse at enhancing her biological fitness by representing a lone disjunct $(F)$ than she is by representing the whole disjunction $(F v G)$. Hereafter, and for ease of discussion, I will refer to someone who holds that perceptual states do admit of EP disjunctive contents as a disjunctionist. ${ }^{10}$

10 To be clear, to say that a perceptual state represents an error-prohibiting disjunctive property has nothing to do with a separate view in the philosophy of perception called disjunctivism. (Cf. Snowdon 1981, McDowell 1982) The disjunctivist holds that the correct description of a subject's perceptual state itself can only be offered as a disjunction: e.g. either $S$ 's state is a representation of F or S's state is a representation of G. As was pointed out in Section 2, some disjunctivists even deny that perceptual states have representational contents at all. (See also Martin 2002) In contrast, the disjunctionist holds that a subject's perceptual state receives a non-disjunctive description, but that what the subject represents is itself a disjunctive object or property, e.g., S's state represents F-or-G. 
We are therefore tasked with answering the following question:

$\left({ }^{*}\right)$ Why is one's representation of $\mathrm{F}$ a representation of $\mathrm{F}$ and not of the (error-prohibiting) disjunctive property $\mathrm{F} v \mathrm{G}$ ?

Burge does not attempt to answer this question. Instead, he turns his efforts in his (2010) toward answering a separate, but related, question that is also traditionally tied to the Disjunction Problem, namely:

$\left({ }^{* *}\right)$ Why is one's representation of $\mathrm{F}$ a representation of $\mathrm{F}$ and not of any alternative candidates $\mathrm{G}, \mathrm{H}$, or I, each of which co-vary with F?

To make sense of the relation between these two questions, it is important now to distinguish two separate versions of the Disjunction Problem. First, to answer $\left(^{*}\right)$ is to attempt to solve what is commonly called the problem of error. The goal here is to explain how nonveridical representation is possible. It is this problem that is the focus of this paper. Secondly, to answer $\left(^{* *}\right)$ is to attempt to solve a different version of the Disjunction Problem, commonly called the problem of functional indeterminacy, where the challenge "is to explain conditions on representation that show why representations represent one range of entities rather than other entities that co-vary with, and in many cases play a role in causing, the representation." (2010: 322)

There is a one sense in which a solution to the indeterminacy problem would thereby solve the problem of error as well; that is, an answer to $\left(^{* *}\right)$ would also constitute an answer to $\left(^{*}\right)$. For, if it can be argued that only one property out of all the alternative candidates that co-vary with that property is the representatum of the subject's perceptual state-and moreover an EP disjunctive property is included in this group of alternative, co-varying properties-then it would appear that identifying this one property as the representatum would thereby preclude the perceiving subject from representing an EP disjunctive property. However, with respect to Burge's own stance toward to the Disjunction Problem, his attempts to answer $\left(^{* *}\right)$, and thereby solve the indeterminacy problem, still leaves the problem of error and an answer to $\left(^{*}\right)$ untouched. To demonstrate my point, let us briefly look at Burge's own solution to the indeterminacy problem, whereupon I will argue that the problem of error is left unresolved.

Burge's dominate strategy for solving the indeterminacy problem is to rule out various candidate disjuncts as alternative representata on the grounds that they are not supported by empirical considerations. With regard to what the frog represents as a fly zips across its visual field, undetached fly part and temporal slices of flies, for example, are excluded as possible alternatives because they do not ground biological explanations of the frog's needs and activities. (2010: 322) Also, the light rays spanning outward from the distal source and entering into the subject's retina cannot be what is represented either, because otherwise our abilities to perceive constancies would be undermined. For these reasons, Burge claims that "[b]iological explanation of animal activity refer to macro-particulars and macro-attributes." (2010: 322-323) He also thinks there is nothing to empirically support the frog's representing human artifacts (e.g. bee-bee) or natural kinds (e.g.fly) as such, but that " $[\mathrm{t}]$ here is some empirical support for taking the frog's perceptual system to have a perceptual attributive like moving body of such and such a size and shape." (2010: 323) 
Suppose we go along with Burge that certain alternative disjuncts are ruled out by empirical considerations, and suppose further, as empirical psychology tells us, that what the frog visually represents when a fly causes this representation is a moving body of such and such type. The problem with this suggestion, I argue, is that it still does not explain how there can be erroneous representation. For even under the proposed description of the frog's representational content, we should like to say that the possibility remains of the frog's representing non-veridically. Perhaps the representation is caused by a moving body with a shape different from the sort the frog represents. Or, perhaps the representation is caused by a series of stationary bodies, each meticulously placed in such a way along a horizontal plane so as to generate the appearance that there is a lone moving body. The point is that given Burge's commitment to VER, he must allow for the possibility of a "wild tokening" associated with that perceptual state. So, through all of Burge's proposed solutions to the problem of the indeterminacy of content, the problem concerning the possibility of error still reemerges: why is it correct to say that the frog represents moving body of such and such type and not instead the EP disjunctive property moving body of such and such type-or-sequence of stationary bodies of such and such type placed along a horizontal plane?

Perhaps Burge may wish to appeal to the fact that the fly's representing moving body of such and such type makes a greater explanatory contribution than the alternative disjunctive property to the biological success of the frog? After all, little moving bodies in the frog's home environment tend to be nutritious flies that are good to eat while meticulously placed stationary objects in a row tend not to be. Fodor thinks this suggestion will lead nowhere, however. With regard to the question of representing fly versus fly-or-bee-bee, he claims that snapping at a fly is no more useful to a frog than snapping at a fly-or-bee-bee in a world where fly-or-bee-bees are reliably flies. (1990: 75) I think Fodor is right on this score: from the standpoint of biology, it does not make any difference which of these objects gets represented by the frog. Either description carries with it the same survival value.

So Burge, I argue, is left without a solution to the problem of error, and the task of the rest of the paper is to offer one on his behalf. Speaking about the Disjunction Problem in general, Burge's main line of response seems to be that "these philosophers pose the problem with no reference to specific empirical work in psychology." (2010: 322) Now, if it is correct that a representation with an EP disjunctive content of macro-particulars does conflict with empirical work in psychology, then we certainly would have good grounds to deny that one's perceptual content could be of an EP disjunctive property.

To pinpoint where this conflict occurs, notice that for Burge, perceptual anti-individualism "is presupposed and relied upon in perceptual psychology." (2005: 1) ${ }^{11}$ So, if it turns out that having a perceptual representation of an EP disjunctive property is incompatible with the truth of Burge's perceptual anti-individualism, then there is reason to believe that it would also be incompatible with findings produced in perceptual psychology. And this is the claim for which I will ultimately argue:

(INC) The truth of Burgean perceptual anti-individualism is incompatible with a perceptual state's having an EP disjunctive property as its referent.

11 This is the central claim for which Burge argues in his (1986b). 
Before we begin it is important to note that INC says nothing about whether perceptual states represent EP disjunctive properties. That claim follows from INC only on the condition that (Burgean) perceptual anti-individualism is true. And while it shares widespread support, certainly not all philosophers are anti-individualists about perceptual content. Burge has spent a career defending its truth, and I mean not to rehash these arguments here. So, my claim will merely be that allowing for perceptual representations with EP disjunctive contents would force one to abandon Burgean perceptual anti-individualism, something many philosophers would not wish to do.

To begin my argument for INC, let us return to our example of lightness constancy discussed in the previous section. We said that on the Burgean view the perceptual system makes use of various formation principles to pick out the distal object that is most likely causally responsible for this proximal stimulation. For instance, we noted that when a luminance contour registered by the retina has a fuzzy as opposed to sharp edge, there is a perceptual norm prescribing that the system represents a uniformity of lightness across the surface of the object. Now, with regard to any one perceptual state produced, there is likely to be a vast number of different such principles and cues that work together in a complicated manner to assign the appropriate content. Solely for the sake of the argument, let us simplify things and suppose that one's abiding by the following principle in the actual world tends to yield veridical representations on most occasions (ignoring, for the time being, all additional principles that the perceptual system regularly follows to perceive lightness constancy):

(ACTUAL) If a luminance contour is registered as having a fuzzy edge, then represent the object as having a uniform degree of lightness (UDL) along its surface; and if a luminance contour is registered as having a sharp edge, then represent the object as having a change in colors or materials (CCM) along its surface.

As we have seen, that the perceptual system abides by principles like ACTUAL is central to Burge's theory of perception. Because the proximal stimulation tied to a subject's retina is too unspecific to determine a unique distal cause (the underdetermination principle), formation principles like ACTUAL generated within the perceptual system in the subject's home environment ensure that the subject represents what is most likely the distal cause over all the alternative causes. Note that ACTUAL is fallibly realized, for if a subject is caused by some wild UDL with a sharp-looking edge to represent a CCM (see the 'sharp spotlight' example from the previous section), the subject's abiding by ACTUAL in this case will generate a non-veridical representation.

Disjunctionism, in contrast, takes each type of perceptual state to represent a disjunction of every type of object or property whose instance has caused this state in the past. And because representations produced by way of the system's registering a fuzzy edge are caused typically by UDLs but occasionally by wild CCMs, and also representations produced by way of the system's registering a sharp edge are often caused by CCMs but occasionally by wild UDLs, the disjunctionist contends that the correct formation principle pertaining to lightness constancy is not ACTUAL, but rather:

(ACTUAL*) If a luminance contour is registered as having a fuzzy edge, then represent the object as having either a UDL along its surface or a wild CCM, and if a luminance contour is registered as having a sharp edge, then represent the object as having either a CCM or a wild UDL. 
Consider Fred who in the actual world is visually confronted with a sidewalk square before him that has a CCM along the far corner of the square (suppose that a puddle lies atop the far corner). His perceptual system registers a luminance contour with a sharp edge. Now, in order to solve the Disjunction Problem, the task is to show why Fred's perceptual state must be formed in accordance with ACTUAL, a state that represents $C C M$, and not with ACTUAL*, a state that represents CCM-or-wild-UDL. The primary question for our purposes is whether Burge's theory of perception has the resources to show why the former principle is the one Fred follows and not the latter. What makes this difficult to show is that as long as we are considering a lone individual in the actual world, we have no reason to prefer one to the other, because Fred's biological fitness in the actual world is unaffected no matter which content we attribute to him.

To see why Fred's perceptual system operates on ACTUAL, then, let us take a look at a second character. Twin Fred is a duplicate of Fred: both have enjoyed the exact same behavioral histories, their cognitive capacities are identical, and all of their experiences are qualitatively indistinguishable. While Fred lives in Actual World (the world in which members of Fred's species evolved), Twin Fred lives in Sharp World (the world in which members of Twin Fred's species evolved). Sharp World is exactly like Actual World in every respect, except for one difference. Whereas fuzzy edges in the Actual World environment are indicative of uniform degrees of lightness, those very same fuzzy edges in the Sharp World environment-due to the different ways light and colors behave in that world-are indicative of discontinuities of lightness, that is, CCMs. For the Burgean anti-individualist, then, Sharp Worldean perceivers operate on the inverse formation principle of ACTUAL, namely:

(SHARP) If a luminance contour is registered as having a sharp edge, then represent the object as having a UDL along its surface; and if a luminance contour is registered as having a fuzzy edge, then represent the object as having a CCM along its surface.

Suppose that Twin Fred in Sharp World confronts a sidewalk square that has a UDL on the far corner of the square (suppose that a shadow covers the far corner), but based on where he is standing, this square is visibly indistinguishable from the square Fred confronts in Actual World. The luminance contour registered by Twin Fred's perceptual system has a sharp edge, and so in accordance with SHARP, Twin Fred represents the surface as having a UDL, not a CCM.

Now, the disjunctionist will interject, based on the same reasoning we gave above, that Sharp Worldean perceivers do not operate on SHARP, but rather on:

(SHARP*) If a luminance contour is registered as having a sharp edge, then represent the object as having either a UDL or a wild CCM along its surface; and if a luminance contour is registered as having a fuzzy edge, then represent the object as having either a CCM or a wild UDL along its surface.

Let us assume for the moment that Fred operates on ACTUAL* and not ACTUAL. Of course, by making this assumption, we must also assume that Twin Fred operates on SHARP* and not SHARP. As we look at the situation with our two characters, it strikes us that Fred's puddle-caused experience in Actual World and Twin Fred's shadow-caused experience in Sharp World are both veridical. Clearly, ACTUAL and SHARP can accom- 
modate this verdict. But notice that ACTUAL* and SHARP* can do the same. For, if we assume that Fred's representational state is CCM-or-wild-UDL, the left disjunct has been satisfied on this occasion; and if Twin Fred's representational state is $U D L$-or-wild-CCM, his state is veridical because the left disjunct is satisfied.

So far, so good. The real trouble begins once we imagine that all of a sudden, and without his knowing, Twin Fred is transported from Sharp World to Actual World-to the very spot, in fact, where Fred now stands looking at the Actual World sidewalk square. The exact same visual scene is set before both of our characters. There has been no change to Fred with this switch, so we can continue to assume that his perception represents the surface as CCM-or-wild-UDL. Twin Fred, on the other hand, is now in a new environment, and (because the sidewalk is tucked underneath a puddle and not a shadow) his retina registers a sharp edge. If it were true that SHARP*, and not SHARP, is the principle on which Twin Fred's perceptual system operates, then when the Actual World puddle causes the system to register a sharp edge, the content of Twin Fred's resulting perceptual state should be: UDL-or-wild-CCM. Notice that because the sidewalk is covered not by a shadow, but by a puddle, Twin Fred's perceptual state is not caused by a UDL along the sidewalk's surface; however, it is caused by a wild CCM. Consequently, this state will turn out to be veridical on this occasion because the right disjunct is satisfied. ${ }^{12}$

Here is the disturbing result with our story. According to Burgean perceptual antiindividualism, because the regularities upon which these formation principles were based in Sharp World are different from the relevant regularities operative in Actual World, the contents of Fred and Twin Fred's experiences should be different. The intuition drawn out by the anti-individualist here is that Fred is correct on this occasion and Twin Fred is not. The formation principles upon which Twin Fred's perceptual system generates perceptual states are to be explained by reference to Twin Fred's home environment, the environment in which his perceptual states are individuated. These principles are realized in his visual system, which is a concrete product of that environment, and which for Twin Fred is Sharp World-an environment wherein sharp edges are indicative of UDLs. Accordingly, his perceptual system should yield $U D L$ representations when sharp edges are registered. So the result is that, while Fred in Actual World represents veridically the surface as having a change of colors or materials, Twin Fred - standing right next to Fred in Actual World - non-veridically represents the surface as having a uniform degree of lightness. This result, at least, is what is demanded by Burgean anti-individualism. But notice that when we assume that perceptual states represent EP disjunctive properties - as when we assume that Fred operates on ACTUAL* and Twin Fred operates on SHARP* - this anti-individualist insight cannot be accommodated. Because both characters on Actual World satisfy either of their respective disjuncts, both of the Freds' experiences turn out to be veridical.

Let us generalize the point. As we saw from the previous section, because of the underdetermination principle, for any perceptual state PS that we typically take to represent property $F$, it is always possible for some wild property $\mathrm{G}$ (distinct from $\mathrm{F}$ ) to causally gen-

12 One might object that while Twin Fred's perceptual state is surely caused by a CCM, it is not a wild CCM for Twin Fred; hence one might deny that the veridicality condition associated with his perceptual state has been met. I address this objection in Section 5.1. 
erate PS, where this instance of PS, generated in this way, is non-veridical. The disjunctionist asks why the formation principle associated with this type of state assigns the system to represent $\mathrm{F}$ but not F v G in worlds where representing this disjunction promotes biological fitness just as well as does representing F. My answer begins by suggesting that in accordance with the Burgean view, for each formation principle upon which subjects operate in the actual world, and which we typically take to assign the system to represent $\mathrm{F}$, there is another possible world in which - due to a different evolutionary background of that world's inhabitants and a different set of physical and psychological laws ${ }^{13}$ - there is a formation principle assigned to the perceptual system of subjects relevantly similar to you and me in that world, which prescribes that the system represents $G$ (not F) when in an identical set of proximal stimulation as subjects in the actual world who are supposed to represent F. So, because the regularities present in each world are different, perceptual anti-individualism requires that two subjects, one in each world, operate on different formation principles; accordingly, the two subjects will represent the referent differently when proximally stimulated in the same way (as demonstrated by the fact that Fred's representation is veridical while Twin Fred's is non-veridical). Thus, if it were true that our perceptual states represent error-prohibiting disjunctive properties (e.g. F v G), and so our actual and counterfactual subjects share the same representational contents, this anti-individualist insight would fall away.

It may be asked: what is the source of the tension between Burgean anti-individualism and disjunctionism? On the Burgean view, the subject-environmental interactions that are relevant to the individuation of a subject's perceptual states are those that reflect natural regularities present in her home environment, as opposed to fluke occurrences, and that generate formation principles so as to overcome the problem of underdetermination of proximal stimulation. These formation principles "serve to privilege certain among the possible environmental causes," (Burge, 2010: 92) and in so doing, allow the perceptual system to select and represent that which is the most likely cause out of the many possible causes. But for a disjunctionist, no one possible environmental cause is privileged, or presented as the most likely cause over the alternatives. For, on a disjunctionist account, the relevant content-individuating interactions associated with a perceptual state type are those had between the subject (or her ancestors) and anything that caused this type of representation in the past. The difference between these two theories is illustrated by the fact the disjunctionist attributes the same representational content to Fred and Twin Fred's perceptual states while the Burgean anti-individualist does not. ${ }^{14}$

13 I elaborate on this difference in evolution background between Fred and Twin Fred in Section 5.2.

14 One may wonder whether the incompatibility claim I have defended in this section (INC) can be extended beyond Burge's theory to other naturalistic theories of content. Indeed, some have argued that Burge's theory is more similar to other theories than Burge would be willing to admit. See Vicente (2012) and Schulte (2013). A full and complete answer to this question would require more space than can be provided in this paper. But I offer a brief consideration here. A theory can utilize this argument for INC, if it takes perceptual states to have contents that are anti-individualistically individuated in accordance with the natural evolution of the perceptual system, wherein the good of that state, namely veridicality, is measured in terms of representational success. To use one example, Millikan's theory $(1984,1989$, and 1990) does not satisfy each of these conditions, because on her account, veridicality is established in terms of biological success and not representational success. Does this point 
To iterate, my conclusion, INC, is not that perceptual states cannot represent EP disjunctive properties. It is instead that evoking EP disjunctive properties associated with each perceptual state directly conflicts with Burgean perceptual anti-individualism's implications, one of which is that Fred must be operating on ACTUAL and not ACTUAL*. Furthermore, if Burge is right that perceptual psychology presupposes perceptual anti-individualism, then it does seem that the notion of representing EP disjunctive properties loses all steam.

\section{Objections and Replies}

Having presented my argument for INC, I now turn to addressing two key objections.

\subsection{Do Fred and Twin Fred share the same contents?}

My argument for INC relies crucially on the premise that if Fred were operating on ACTUAL* (which outputs a CCM-or-wild-UDL representation) then his resulting perceptual state would share the same EP disjunctive content as that of Twin Fred who, operating on SHARP*, comes to have a UDL-or-wild-CCM representation. It follows that the environmental features that correspond to Fred's $C C M$ representation type are the same as those that correspond to Twin Fred's wild CCM representation type (the same goes for Fred's wild UDL and Twin Fred's UDL representation types). One might object that the disjuncts represented in Fred's perceptual state are different from those represented in that of Twin Fred. The idea here would be that a property's status as wild varies from world to world, such that wild CCMs in Actual World are CCMs whose edges appear fuzzy, while wild CCMs in Sharp World are CCMs whose edges appear sharp. If this were correct, then the opponent could charge that the CCM causing Twin Fred's perceptual state while he is in Actual World does not fall in the extension his wild CCM representation type; moreover, the disjunctionist would then be free to agree with the Burgean anti-individualist that Twin Fred's perceptual state is non-veridical on this occasion, since the object causing his state is neither a UDL nor a wild CCM.

The central question, then, is whether the CCM that Fred and Twin Fred face in Actual world falls in the extension of Twin Fred's wild CCM representation type. Answering this question hinges on our understanding of what constitutes a wild object or property in general. A wild object is an item that triggers a perceptual state whose content we typically take not to correspond with that item. Part of what makes something wild is that it leaves the individual liable to make (what we would ordinarily consider to be) a mistake. But the objects we consider to be wild are not simply those that a subject misrepresents as something else. Rather, these are objects under a certain description. Regarding one of Fodor's own examples on this topic, we note that humans do not often mistake a cat for a dog, but

preclude Millikan from utilizing my argumentative strategy? Not necessarily. If Millikan's notion of veridicality, grounded in biological well functioning, can nevertheless capture the point that perceptual content types are what they are in virtue of natural regularities present in the home environment, I do not see, on the face of it, why a theory like hers could not deploy this type of argument for INC. 
they do often mistake a cat-on-a-dark-night for a dog. ${ }^{15}$ That is the reason why a cat-on-adark-night is wild in relation to our $d o g$ experiences but a cat simpliciter is not. So, wild objects, I claim, are those that have led, or are liable to lead, the perceiver astray in virtue of the description associated with that object. Objects described in one way may be wild for one group of perceivers but may be non-wild for another. For instance, there are other sorts of creatures, like non-human animals or other possible beings, that are better at perceptually discriminating a dog from a cat-on-a-dark-night than are humans, so a cat having this description would not constitute a wild object in relation to that creature's dog experiences.

So wild objects are those that leave the perceiver prone to error, and what makes one "prone to error" is understood relative to the perceiver's own perceptual abilities and limitations. My suggestion, therefore, is that an object or property's status as "wild" is not established relative to the environment one happens to be in when the representational state is produced. Rather, it is established relative to the subject's home environment- the environment in which the subject's perceptual abilities were developed.

Returning to our two characters, it follows from what I have just said that what constitutes a wild CCM representation for Fred is not the same as what constitutes a wild CCM representation for Twin Fred. For, Fred is liable to mistake a UDL for a CCM that has a fuzzy-looking edge, while Twin Fred, coming from Sharp World, is liable to mistake a UDL for a CCM that has a sharp-looking edge. Thus, while both characters possess wild $C C M$ representation types, they are each associated with different descriptions and so do not admit the same objects in their extension. A wild CCM for Fred is a CCM-with-afuzzy-looking-edge; a wild CCM for Twin Fred is a CCM-with-a-sharp-looking-edge.

So, the answer to the objector's question of whether the CCM Twin Fred confronts in Actual World falls in the extension of his wild CCM representation type depends on whether the CCM fits the description of being wild for Twin Fred. I argue that it does. For, Twin Fred in Actual World now gazes at a CCM that looks to him as having a sharp edge. This is exactly the description we associate with wild CCMs that affect Sharp Worldeans like Twin Fred. Granted, the explanation for why this wild CCM in Actual World has this sharp look is different from the explanation for why wild CCMs in Sharp World have that same look. Whereas a wild CCM in Sharp World is brought about by some anomalous event within that world (e.g. an experimenter's manipulation of the subject's visual scene or some freak, accidental occurrence in nature), the wild CCM Twin Fred confronts in Actual World is explained by the natural regularities present in an environment that Twin Fred now happens to inhabit. But I do not see why this difference should prompt us to deny that Twin Fred is nonetheless deploying the same wild CCM representational ability across both types of cases. That the causal explanation of a wild object $\mathrm{O}$ in one situation is different from the causal explanation of a wild $\mathrm{O}$ in another does not imply that these O's are not instances of the same category of being wild for the perceiver. On two separate occasions, I may encounter a cat-on-a-dark-night and mistake it for a dog. The fact that one cat-on-a-dark-night is causally explained by an alley cat that has lived its whole life on this street and has never wandered away, while the other one was placed on the street by God only four seconds before I arrived, is no grounds for claiming that one such cat is wild while the other is not. Both cats have the same description and both are liable to make me

15 See Fodor 1990: 59. Thanks to an anonymous referee for raising this point. 
mistake this object for a dog, which I claim is sufficient to count both of them as wild objects in relation to my dog experiences. Thus, even though the wild CCMs in Sharp World are causally explained differently from the CCM Twin Fred confronts in Actual World, they still each receive the same description; for this reason, they each fall in the extension of Twin Fred's wild CCM representation type. Therefore, against the objection, it remains that on the assumption that Fred and Twin Fred operate on ACTUAL* and SHARP* respectively, their resulting perceptual states caused by a CCM in Actual World will share the same content.

\subsection{DO DIFFERENT EVOLUTIONARY BACKGROUNDS ENTAIL DIFFERENT FORMATION PRINCIPLES?}

For a separate objection, one might argue that if Fred and Twin Fred's perceptual states (as when caused by an Actual World puddle) share the same representational content on a disjunctionist account, then they must be operating on the same formation principle (that is, ACTUAL* and SHARP* collapse into the same principle); but because the evolutionary history of the subject plays a role in establishing the formation principles on which she generates perceptual states, and furthermore Fred and Twin Fred enjoy divergent evolutionary histories, it cannot be that, by disjunctionist lights, the two characters' perceptual states share the same representational content.

Before responding to the objection, let me make one important clarification. The challenge of the Disjunction Problem is to explain why one individual, Fred, represents $C C M$ and not CCM-or-wild-UDL in a world where it makes no evolutionary difference how the perceptual content is described. So meeting this challenge requires making a comparison between two versions of Fred within the same home environment: one wherein the formation principle leads him to represent $\mathrm{F}$ and one wherein the principle leads him to represent F v G. In accord with the Disjunction Problem, we stipulate that these two (Actual) Freds are indistinguishable from an evolutionary point of view. To answer this challenge of why attributing $C C M$ to Fred's state is preferable to attributing the EP disjunctive property, I then set up a thought experiment that compares two characters between different home environments. And answering the main challenge does not require us to further stipulate that Fred and Twin Fred, each from different home environments, are indistinguishable evolutionarily. Our only task is to show that Fred and Twin Fred's perceptual representational states (when caused by the same distal object) are the same by disjunctionist lights, while the Burgean view says they are not.

To adequately respond to this objection, we must answer the following two questions: In what sense do Fred and Twin Fred differ from an evolutionary standpoint? And, does this evolutionary difference imply that they cannot, on the assumption of disjunctionism, be operating on the same formation principle when they each confront an Actual World puddle?

In answer to the first question, I claim that Fred and Twin Fred differ evolutionarily only to the same extent as does an Earthling and a Twin Earthling. First consider the way in which someone on Earth and someone on Twin Earth (an environment wherein the stuff that falls from the sky and fills its lakes and rivers is composed of $\mathrm{XYZ}$ and not $\left.\mathrm{H}_{2} \mathrm{O}\right)^{16}$

16 See Putnam (1975) and Burge (1982). 
share the same evolutionary background. It is part of the template of standard Twin Earthstyle scenarios that the two main characters are behaviorally indistinguishable. Water and twater serve the same function when comparing inhabitants on Earth and inhabitants on Twin Earth. On each occasion in which the Earthling drank a glass of water on a hot day, the Twin Earthling drank a glass of twater on a hot day. And, for every time the Earthling swam in a water-filled lake, the Twin Earthling swam in a twater-filled lake. So, when we compare individuals between the two environments, we see that the Earthling (on Earth) and the Twin Earthling (on Twin Earth) are on a par with respect to their biological fitness. In this regard, neither character within his own respective environment is at an evolutionary advantage over the other.

However, I hold that there is an evolutionary difference between the two characters in the sense that which items each character interacted with so as to promote her own biological fitness are not the same. Whereas the Earthling and the Earthling's ancestors depend on water (composed of $\mathrm{H}_{2} \mathrm{O}$ ) for their survival, the Twin Earthling and the Twin Earthling's ancestors depend on a different kind of stuff, twater (composed of XYZ), for theirs. The Earthling receives crucial nutrition from drinking water that she would not receive had she been drinking twater. Thus, the interactions that cater to the Earthling's own biological pursuits, and moreover contribute to the individuation of her perceptual and doxastic states, are those occurring between the Earthling (or her ancestors) and instances of water. But with regard to the Twin Earthling, the biologically relevant interactions were those occurring between the Twin Earthling (or her ancestors) and instances of twater. This difference, though it does not prompt any variation in behavior or biological advantage between the two characters, is clearly relevant to the evolution of the species of which the Earthling and the Twin Earthling are respective members.

Similarly, my claim is that Fred on Actual World and Twin Fred on Sharp World are behaviorally indistinguishable; they are also on a par evolutionarily in the sense that the items with which they interact, and also the perceptual states they produce as their retinas are proximally stimulated, ensure the same degree of biological fitness for the two Freds within their own respective environments. Neither character is more at an advantage biologically over the other. Nevertheless, clearly there is an evolutionary difference between the two characters in the sense that the natural regularities on which Fred relies for his survival are not the same regularities on which Twin Fred relies for his. Fred's, but not Twin Fred's, ability to flourish as a biological creature is due, in part, to the fact that his perceptual system represents a uniform degree of lightness on a surface when it registers a fuzzy edge, because in Actual World fuzzy-edged perceptual registrations are most typically caused by uniformities of lightness. So, while neither of our two characters is more or less biologically fit with respect to his own environment than the other, each character's fitness is explained by a different set of natural regularities associated with each world. The Burgean anti-individualist insists that these differences in the evolutionary history of each subject be reflected in how the contents of their perceptual states are described. That is why an anti-individualist's interpretation of the thought experiment assigns separate formation principles, ACTUAL and SHARP, to Fred and Twin Fred respectively, operations on which yield different outputs when the two characters are placed in the same proximal stimulation.

The disjunctionist cannot say the same, however, for on such an account, a perceptual state is said to represent a disjunction of everything at least one of whose instances has 
caused this state in the past. What this implies is that ACTUAL* and SHARP* collapse into the same formation principle, such that they yield the same EP disjunctive content as output regardless of how the subject is proximally stimulated on an occasion. By operating on this lone formation principle, while Fred and Twin Fred achieve the same degree of biological success as the other within their own respective environments, the disjunctionist's description of their perceptual contents fails to capture the fact that the set of interactions that catered to Fred's success is not the same set as the one that catered to Twin Fred's success.

\section{Conclusion}

The presenter of the Disjunction Problem asks why on one's theory it is correct to describe a subject as representing a non-disjunctive property $(F)$ but not to describe her as representing an EP disjunctive property $\left(F_{v} G\right)$. Biology alone will not help as an answer because in worlds where ( $F \vee G)$ 's are reliably $F$, the subject is equally biologically well off no matter which description is used. In this paper I have attempted to answer this question on behalf of Burge's theory. I argued that choosing the former description $(F)$ is to be preferred to the latter description ( $F v G)$, because the latter is incompatible with Burgean perceptual anti-individualism. As a result, Burgeans about perception need not be terribly bothered by the Disjunction Problem.

\section{REFERENCES}

Burge, T. 1982. Other bodies, in Woodfield (ed.) Thought and Object, New York: Oxford University Press: 97-120.

Burge, T. 1986a. Cartesian error and the objectivity of perception, in Pettit, P. \& McDowell, J. (eds.) Subject, Thought, and Context. Clarendon Press.

Burge, T. 1986b. Individualism and psychology, The Philosophical Review, 95 (1): 3-45.

Burge, T. 2003a. Perceptual entitlement, Philosophy and Phenomenological Research, 67 (3): 503-548.

Burge, T. 2003b. Memory and persons, The Philosophical Review, 112 (3): 289-337.

Burge, T. 2005. Disjunctivism and perceptual psychology, Philosophical Topics, 33 (1): 1-78.

Burge. T. 2007. Foundations of Mind, New York: Oxford University Press.

Burge, T. 2010. Origins of Objectivity, New York: Oxford University Press.

Campbell, J. 1987. Is sense transparent? Proceedings of the Aristotelian Society, 88: 273-292.

Dretske. F. 1981. Knowledge and the Flow of Information, Cambridge, MA: MIT Press.

Fodor, J. 1984. Semantics, Wisconsin style, Synthese, 59 (3): 231-250.

Fodor, J. 1990. A Theory of content I, in A Theory of Content and Other Essays. Cambridge, MA. MIT Press.

Gauker, C. 2012. What do your senses say? On Burge's theory of perception, Grazier Philosophische Studien, 85: 311-325.

Martin, M. 2002. The Transparency of experience, Mind and Language, 17: 376-425.

McDowell, J. 1982. Criteria, defeasibility and knowledge, Proceedings of the British Academy, 68: 455-479.

Millikan, R. 1984. Language, Thought, and Other Biological Categories, Cambridge, MA: MIT Press.

Millikan, R. 1989. Biosemantics, The Journal of Philosophy, 86 (6): 281-297.

Millikan, R. 1991. Speaking up for Darwin, in Loewer \& Rey (eds.) Meaning in Mind: Fodor and His Critics, Cambridge, MA: Basil Blackwell.

Neander, K. 1995. Misrepresenting and malfunctioning, Philosophical Studies, 79 (2): 109-141. 
Palmer, S. 2002. Vision Science, Cambridge, MA: MIT Press.

Putnam, H. 1975. The Meaning of 'meaning', Philosophical Papers, Vol. 2: Mind, Language, and Reality. Cambridge: Cambridge University Press.

Rescorla, M. 2013. Millikan on honeybee navigation and communication, in D. Ryder, J. Kingsbury, \& K. Williford (eds.) Millikan and Her Critics. Malden, MA: Wiley-Blackwell.

Schulte, P. 2013 (published online first) Perceptual representations: A teleosemantic answer to the breadthof-application problem. Biology and Philosophy, 28 (4).

Snowdon, P. 1981. Perception, vision, and causation. Proceedings of the Aristotelian Society, 81: 175-192.

Stampe, D. 1977. Towards a causal theory of linguistic representation, in French, P., Euhling, T. \& Wettstein, H. (eds.) Midwest Studies in Philosophy, 2: $42-63$.

Vicente, A. 2012. Burge on Representation and Teleological Function, Thought, 1 (2): 125-133.

Jon Altschul is an assistant professor of philosophy at Loyola University New Orleans. His research focuses primarily on the philosophy of perception, the epistemology of perceptual belief, and the overlap between these two areas.

Address: Department of Philosophy, Loyola University New Orleans, Box \#107, New Orleans, LA 70118. E-mail: jlaltschul@gmail.com 